\title{
DEVELOPMENT AND TESTING OF TRACTOR-MOUNTED FERTILISZRS SPREADER
}

\author{
A. M. El-Sheikha* $\quad$ R. A. Hegazy ${ }^{\dagger}$
}

ABSTRACT

The lack of efficiency and effectiveness in fertilizer applications in many crops has been continues challenge to sustainable use of inorganic/commercial fertilizers, the right balance in fertilizer application is an important element in nutrition management in Egypt, and promoting efficient and effective use of fertilizer has emerged as an important target of policies and programs in recent decades. However, fertilizers distribution in Egypt is still mostly done manually due to small field sizes, and it is laborious, costly, and the spread pattern is not accurate. So manufacturing such small fertilizer distributor that can be mounted on a tractor or any smaller carriage could provide a simple mechanized solution for fertilizing small fields in Egypt. So, this study is carried out to manufacture and test a tractor-mounted spreader and this could help farmers to increase efficiency and effectiveness in fertilizer use in small scale applications. Fertilizers spreader consisted of; frame, spreading material hopper, agitator, spreading disc with four adjustable blades (fins), and electrical control unit. In stationery mode experiments, Differences of distribution density in both sides of the spreader have been measured under different possible combinations of settings till best results obtained. Many tables have generated to get the recommended setting to deliver specific amount with best uniformity. Also, the spreader has been calibrated to get the repression equations to be the base of using different fertilizers in field based on the recommended tractor forward speeds in field. For spreading Urea in field, placing 1 fin in middle and 3 fins at end right on spreading disc and setting spreading disc speed to $550 \mathrm{rpm}$ is better option to have $5.5 \mathrm{~m}$ effective swath length. Where using $250 \mathrm{rpm}$ spreading disc speed is one of settings can achieve the favorable effective swath width of $5.5 \mathrm{~m}$ with compound fertilizer. For maximum spreading

\footnotetext{
* Assistant Professor, Agric. Eng. Dept., Faculty of Agric., Damietta University

${ }^{\dagger}$ Assistant Professor, Agric. Eng. Dept., Faculty of Agric., Kafrelsheikh University
} 
width, it is recommended to set the spreading disc speed to 700 rpm and 2 disc fins located in center and 2 in their end right for both urea and compound fertilizer. Muriate of Potash fertilizer (MOP) as a fine crystal fertilizer with recommended amount less than $20 \mathrm{~kg} / \mathrm{feddan}$ in most of fields not easy to be distributed by the spreader under $4 \mathrm{~km} / \mathrm{h}$ forward speed or less. Average SPAD values (Chlorophyll meter values) showed no significant differences within each subplot and in different locations for all application rates. The maximum difference between average lowest and highest SPAD values for plots that have been spread by the machine was $8 \%$ when the machine was spreading $75 \%$ of recommended rate. Lowest values were 3 and $4 \%$ for 50 and $100 \%$ of recommended rates. In manual broadcasting there was difference of $15 \%$ between lower and highest value of SPAD in different plot locations.

Keyword: Fertilizer spreader, distributing pattern, uniformity, spreading disc.

\section{INTRODUCTION}

Tn Europe, fertilizer particles are mainly spread by means of centrifugal spreaders (Persson, 1998). The spatial distribution of the

particles across the field has an important influence on the growth of the crop. Mostly one tries to achieve an even distribution of particles across the field, i.e. a constant mass of fertilizer per unit soil area. Application of too small or too large doses at certain spots will results in qualitative and quantitative yield losses (Sogaard and Kierkegaard, 1994) and can lead to losses of profits of $10 \%$ and more (Prummel and Datema, 1962). Excessive application obviously can avoid nutrient deficiency. On the other hand, it results not only in additional costs and the above-mentioned yield losses, but also causes pollution of groundwater and surface water (Parris and Reille, 1999). The different components of fertilizer applicators, especially disc- based spreading, are important as well as characteristics of the fertilizers to achieve the favorable distribution pattern and uniformity. Hofstee (1993) mentioned that the uniformity of spread pattern of fertilizers is become more important for both economic and environmental reasons to ensure that fertilizers are not applied unnecessary. Morad (1990) showed that the 
uniformity of fertilizer distribution affected by spreader speed, blade pitch, spreader dip angle and fertilizer type. Larry and Bandel (2002) reported that oval pattern is the best pattern for both the single or double disc fertilizer spreaders because the effective overlap with this pattern was about $60 \%$ of the theoretical width that was about $20 \%$ of the swath width must be overlapped, also the pyramid pattern was an acceptable pattern because the effective overlap was only $50 \%$ of the theoretical width. Hassan et al. (2005) showed that the high degree of uniformity can be achieved by using the spinner speed of $500 \mathrm{rpm}$, (spinner diameter $500 \mathrm{~mm}$ ) blade angle of $15^{\circ}$, spinner dip angle $0^{\circ}$, spinner height 500 $\mathrm{mm}$, straight $\mathrm{C}$-shape blade. Yildirim and Kara (2003) investigated the effect of vane height on distribution pattern with different flow rates. They used a tractor-propelled spreader with a $500 \mathrm{~mm}$ flat disc and two materials, triple superphosphate [TSP $-\mathrm{Ca}\left(\mathrm{H}_{2} \mathrm{PO}_{4}\right)_{2} \cdot \mathrm{H}_{2} \mathrm{O}$ ] and calcium ammonium nitrate $\left[\mathrm{CAN}-\mathrm{Ca}\left(\mathrm{NO}_{3}\right)_{2} \cdot \mathrm{NH}_{4} \cdot \mathrm{NO}_{3}\right.$ ]. They reported that the most uniform distribution was obtained with a vane height of $35 \mathrm{~mm}$ and orifice diameter of $35 \mathrm{~mm}$ for both fertilizers in their particular spreader experiments.

To evaluate fertilizer spreaders, several types of distribution patterns can be measured in order to evaluate the performance of a certain spreader for a certain type of fertilizer. The transverse distribution is the only standardized distribution pattern (ISO, 1983). Measurement of the transverse distribution is done in spreading halls. In these halls most external factors influencing distribution patterns are excluded. The most realistic method is the placement of a row of collection trays in the field, perpendicular to the driving direction of the spreader. The captured particles are weighed and the transverse distribution is obtained. Owing to uncontrollable external factors, such as wind and field conditions, it is impossible to compare the performances of different combinations of spreader and fertilizer type (Reumers et al., 2003). Lawrence et al., (2006) were really the first to consider the "on the ground" or "in field' pattern. They did this by considering a two dimensional spreader footprint rather than a single row of trays to catch fertilizer, the footprint could then be superimposed on the ground and subsequent overlaps taken into account. That work exploded the myth that we were spreading with 
"CV's" of 15 and 25\%. In his field experiments an "in-field" CV of $42 \%$ was estimated for spreading over a number of farms. That work was verified to a very large extent by Piron et al. (2010).

As proper design of such machines is essential, however, experience and experimental methods are mostly used in their design, so it is difficult to achieve an optimal design. Hao et al. (2013) proposed an approach for research and to optimized design of a fertilizer spreader based on an outer groove wheel Fertilizer spreaders (OGWFS) and granular compound fertilizer. They built a 3D discrete element method (DEM) model using a 3D CAD model of the fertilizer spreader and construct a fertilizer particle analysis model using spherical particles. By changing the CAD model of the machine, they were able to analyze fertilizer spreaders of different structures and sizes and the preliminary results indicated the validity and effectiveness of DEM analysis. Additional to CAD models, three dimensional ballistic models was developed to investigate the effect of spin on the trajectory of fertiliser grains in the air and their subsequent landing position. Simulations indicated a major effect on the landing positions of individual grains although the magnitude was dependent on fertiliser- and spreader characteristics. Deviations up to $33 \%$ of the total travelled distance in the direction of the initial horizontal velocity vector were found (Cool et al., 2014).

So, the main objectives of the study were to design and manufacture tractor-mounted fertilizer distributor based on using newly designed spreading disc, and to evaluate the distribution pattern of the spreader with optimization of the fertilizer distribution rate based on the time consumed and target vehicle' forward speed.

\section{MATERIALS AND METHODS}

\section{Fertilizers spreader components}

Fertilizers spreader consisted of; frame, spreading material hopper, agitator, spreading disc and electrical control unit. Spreader' components and its arrangement as in Fig.1

\subsection{Frame}

The fertilizer spreader frame has been made of steel to carry; hopper and its bracket; hoper platform, dosage slide; spreading disc and its fins. The overall 
dimensions of the frame with the attachments were 470x500x1100 mm as length, width and height with $46 \mathrm{~kg}$ weight. Three points for hitching the spreader with the tractor have been located for levelling the spreader above the soil with recommended distributing height $(700 \mathrm{~mm})$.

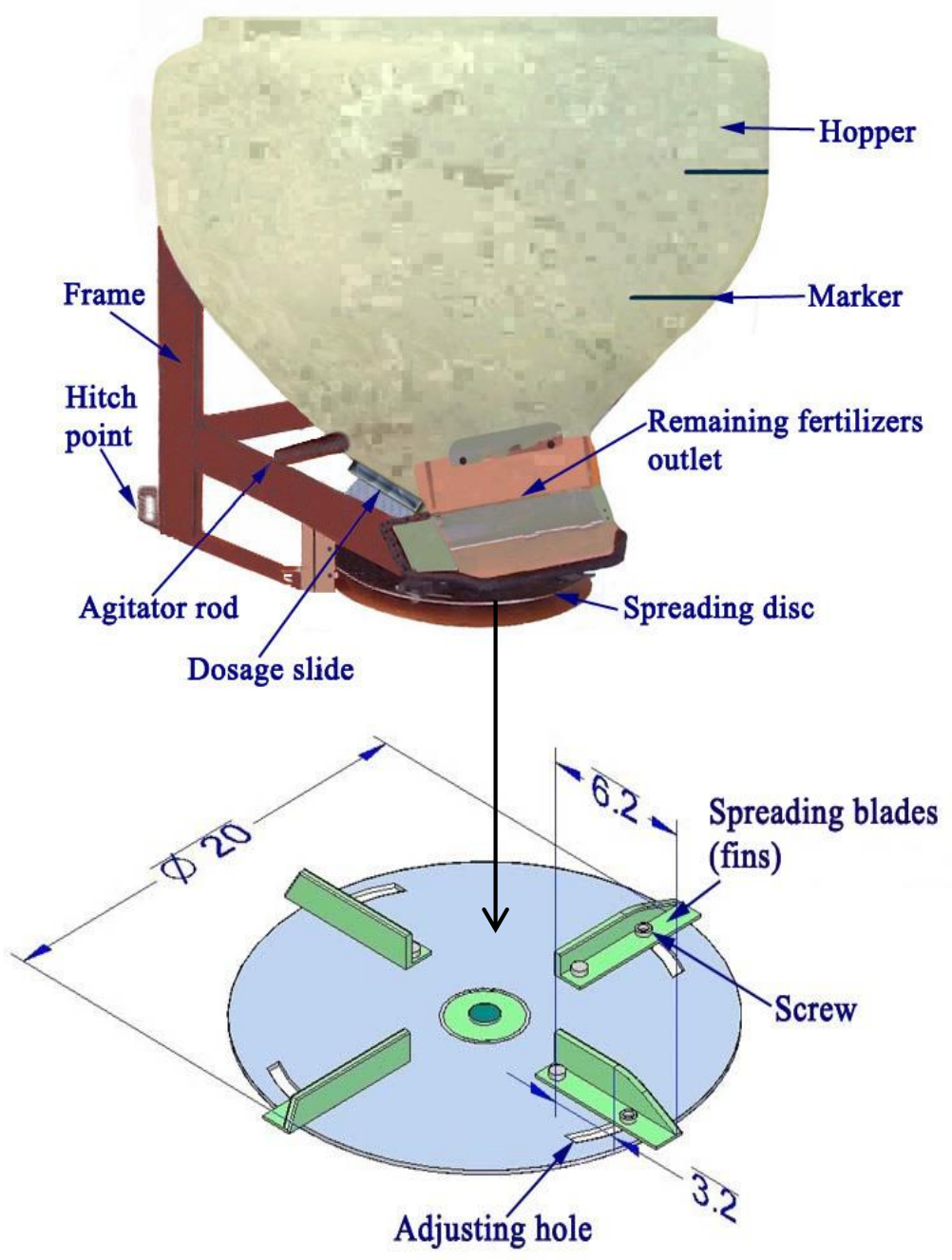

Fig. 1 Manufactured fertilizers spreader and its components

\subsection{Spreading disc}

Spinning type spreading disc has been manufactured from steel equipped with 4 fins with possibilities of adjusting the pitch angle of each fin. Spreading fins are fixed using hexagon screws and Allen screws. Each fin has ability to be adjusted on one of three locations right, left and middle 
within for in-depth analysis of effect of spreading fins arrangement on distribution uniformity.

\subsection{Electrical control unit}

Electrical control unit controls and regulates the speed of the spreading disc and it used to close and open gate which is locating above the dosage slide opening arm too. Main components of the electrical control unit included; derive motor, speed sensor, distribution switch box, and battery cable. Technical data are presented in Table 1.

Table 1: Distributor' electrical unit

\begin{tabular}{|l|c|}
\hline Operating voltage, $\mathbf{V}$ & $12-24$ \\
\hline Fuse, A & 25 \\
\hline Power of driver motor (spreading disc), W & 60 \\
\hline Power of agitator, W & 150 \\
\hline Speed range, rpm & 40 to 700 \\
\hline Speed of standard agitator, rpm & 55 \\
\hline Power consumption of motor, A & $\begin{array}{c}\text { Start up to } 25 \text { - normal } \\
\text { operation up to } 13\end{array}$ \\
\hline
\end{tabular}

\subsection{Hopper}

Plastic tank has been modified and used to hold the fertilizers with volume capacity up to 651 , an option to use a vertical agitator and it is powered also by using the same motor. The hopper has down realizing hole and platform of $850 \mathrm{~mm}$ in diameter (Fig. 2).

\section{Study Sites, experiments variable and procedures}

\subsection{Stationery mode experiments}

Stationery mode experiments conducted in free area of concrete pavements and flat level sites with no side slope near Department of Agricultural Engineering, Kafrelsheikh University during year 2014/2015 to analyze and evaluate the distribution pattern of a newly manufactured fertilizer spreader. Different fertilizers types, spreading disk speeds, fins position on spreading disc, and dosage slide control arm setting have been chosen to determine the effective path width and overlapping. Analyzing and evaluation of distribution pattern of fertilizer done under different spreading disk rotational speeds $(250,400,550,700 \mathrm{rpm})$. Three types of 
fertilizers are used; Prilled Urea, Compound Fertilizer, and Muriate of Potash (Table 2). Stationery experiments included different dosage slide opening settings ( 1 to 6 on scale adjustable manually by moving dosage slide control arm to required scale Fig. 2a) and fins position on spreading disc (right, left and middle) as variables too. Distribution pattern and effective width/overlap have been tracked using catching trays with grid baffles (Fig. 2 b) to calculate the density of the distributed fertilizers and the rate of application as gram per unit area and to validate the spreading pattern too. Percentage of differences on both sides for the amount distributes by the spreader can be calculated using the below equation:

$$
\mathbf{D}=\frac{\mathbf{X}_{\mathrm{R}}-\mathbf{X}_{\mathbf{L}}}{\mathbf{X}_{\mathbf{R}}}
$$

Where:

$\mathrm{D}=$ Percentage of differences, $\%$

$\mathrm{X}_{\mathrm{R}}=$ weight of material collected from right trays, $\mathrm{g}$.

$\mathrm{XL}=$ weight of material collected from left trays, $\mathrm{g}$.

Table 2: Specification of fertilizers used in experiments

\begin{tabular}{|c|c|c|c|}
\hline Fertilizer & Prilled urea & Compound Fertilizer & Muriate of Potash \\
\hline $\begin{array}{l}\text { Main } \\
\text { Components }\end{array}$ & $\begin{array}{l}\text { Nitrogen: } 46 \% \\
\text { min., Moisture: } \\
0.5 \% \text { max., } \\
\text { Biuret: } 1.0 \% \\
\quad \max .\end{array}$ & $\begin{array}{c}\text { Nitrogen: } 14 \% \text { min. } \\
\text {, Phosphorous: } 14 \% \\
\text { :min., Potash: } 14 \% \text { min., } \\
\text { MgO: } 2 \% \text { max., Moisture } \\
\text { content: } 2 \% \max \end{array}$ & $\begin{array}{c}\text { Potassium: } 50 \% \text { min., } \\
\text { Chloride: } 46 \% \text { min., } \\
\text { Moisture: } 2.0 \% \text { max., } \\
\text { NaCl: } 2.0 \% \text { max., } \\
\text { Mg: } 0.2 \% \max \end{array}$ \\
\hline $\begin{array}{l}\text { Commercial } \\
\text { name }\end{array}$ & Urea $46 \%$ & NPK 14-14-14 & $\begin{array}{c}\text { Muriate of Potash 0- } \\
0-60(\mathrm{MOP}) \\
\end{array}$ \\
\hline $\begin{array}{l}\text { Chemical } \\
\text { formula }\end{array}$ & $\mathrm{Co}\left(\mathrm{Nh}_{2}\right)_{2}$ & $\mathrm{~N}-\mathrm{P}_{2} \mathrm{O}_{5}-\mathrm{K}_{2} \mathrm{O}$ & $\begin{array}{l}\text { Potassium Chloride } \\
(\mathrm{KCl})\end{array}$ \\
\hline State & $\begin{array}{l}\text { Granular- } \\
\text { Compost }\end{array}$ & Granular-Compost & $\begin{array}{c}70 \% \text { random - } \\
\text { unequal size }\end{array}$ \\
\hline $\begin{array}{l}\text { Granular } \\
\text { size }\end{array}$ & $0.85-2.80 \mathrm{~mm}$ & $2-5 \mathrm{~mm}$ & Mix- uneven size \\
\hline Release type & Quick & Quick & Quick \\
\hline Classification & $\begin{array}{l}\text { Compound } \\
\text { Fertilizer }\end{array}$ & Compound Fertilizer & $\begin{array}{l}\text { Potassium Fertilizer - } \\
\text { Compound Fertilizer }\end{array}$ \\
\hline
\end{tabular}




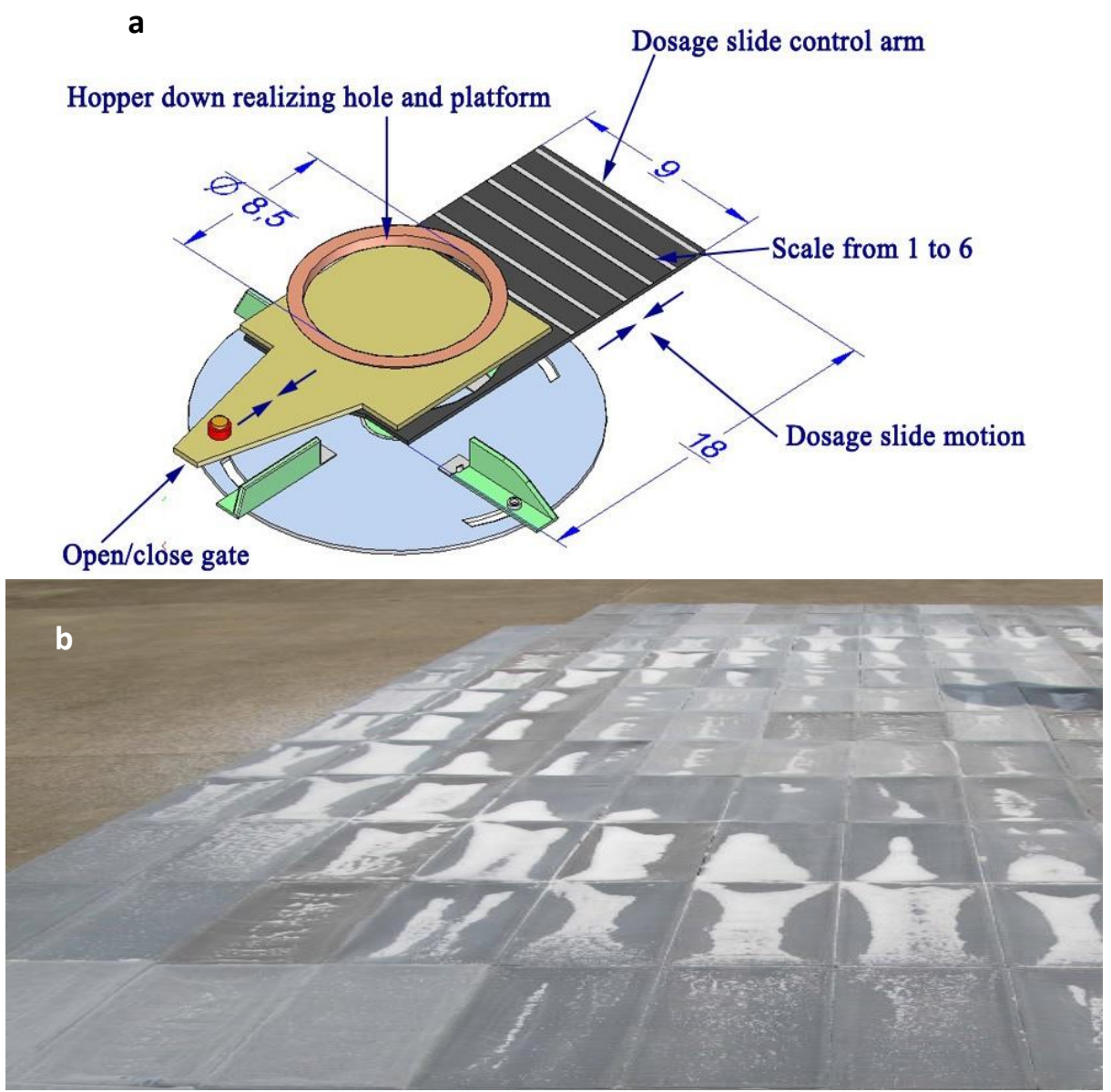

Fig. 2 : a Dosage slide control arm and open/close gate, b: catching trays with grid baffles

After spreading, the contents in trays represented mass distribution of the entire spread pattern area. Data obtained and generated from first experiments was guide for adjusting the spreader for better distribution pattern and to determine the right setting. With particular field sizes and available forward speeds, the time required to spread recommended fertilizer rate can be derived, which will depends more on field size and length, guide tables have been generated to serve as references or standard in using tractor mounted spreader for fertilizer spreading. Calibration done to the spreader with all possible delivering amounts by using all possible settings, and regression equations were delivering, and all calculation done twice based on using tractor with two forward speeds 
2.75 and $4 \mathrm{~km} / \mathrm{h}$. Calibration of the spreader under specific setting to be used in field can be done using the below equations:

$$
M=\frac{4200 \times Q}{A}
$$

Where, $\mathrm{M}$ is the applicable rate in $\mathrm{kg} / \mathrm{feddan}, \mathrm{A}$ is the area in $\mathrm{m}^{2}$ which equal to pass length into spreading width, and $\mathrm{Q}$ is the amount required in $\mathrm{kg}$, which can be found as by the following:

$$
\frac{\mathbf{T X} \mathbf{q}}{\mathbf{t}}
$$

Where, $\mathrm{q}$ is the amount distributed in stationery mode in $\mathrm{kg}, \mathrm{t}$ is the time for distributing $\mathrm{q}$ in $\mathrm{min}$, and $\mathrm{T}$ is the pass time in field in min, this time can be calculated by the below equation:

\section{X 60 \\ $\overline{\mathrm{SX1000}}$}

Where, $\mathrm{L}$ is the pass length in $\mathrm{m}$ at recommended spreading width, and $\mathrm{S}$ is the speed in $\mathrm{km} / \mathrm{h}$ for the vehicle that carries the distributor.

\subsection{Field experiments}

Field experiments conducted in private farm in Kafrelsheikh governorate after 25 days of rice transplanting during season 2015. The overall experimental area was $2875 \mathrm{~m}^{2}$. An area of $1725 \mathrm{~m}^{2}$ has been used and divided into 3 subplots $\left(11.5 \times 50 \mathrm{~m}^{2}\right.$ each). Each subplot has four subsub plots for manual/mechanical spreading comparison and for addressing the effect of spreading different rates on field distribution pattern. Three rates have been used $(100 \%, 75 \%$ and $50 \%$ of compound fertilizer and urea of recommended rates for the spreader and $100 \%$ of recommended rate only for manual) (Fig. 3). Two more subplots with $1150 \mathrm{~m}^{2}$ assigned to track the distribution pattern for continuous spreading in two passes and maximum spreading width. Field experimental design conducted with one level randomized split-split plot. Distribution of fertilizers by using manufactured spreader done with three levels of spreading rates, and distribution method considered as a variable to compare between spreader and traditional spreading method (manual broadcasting). Distribution width for mechanical spreader was $5.5 \mathrm{~m}$ in all subplots except for one subplot where the spreaders run with maximum spreading width for 
fertilizers. Manual fertilizer broadcasting will be the control and to be compared with the spreader during field testing.

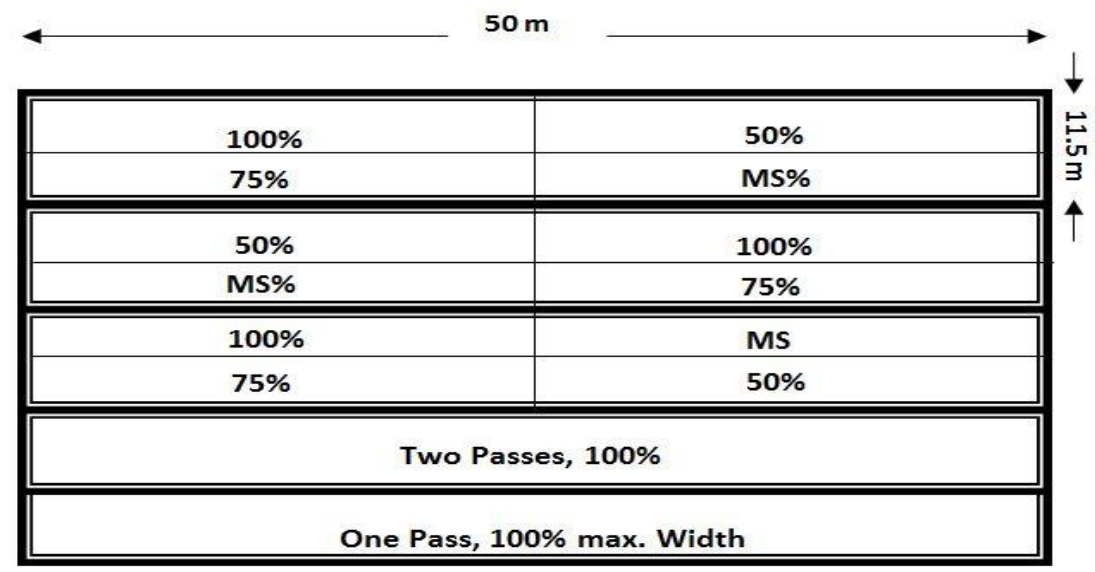

Fig. 3 Field experimental design of manual/mechanical fertilizer distributing and spreading rates comparison

For tracking changes and uniformity in field which may vary by applying different fertilizer rates, uniformity of distribution has recorded by using eight trays located perpendicularly on tractor travel direction as well as manual broadcasting sides to collect amount of fertilizers fall down on it after each replication ( 5 trays each side have been used with maximum spreading width trails). All amount in the trays recorded and average value in each side generated to see the differences as an indicator to the field distribution patterns. Chlorophyll SPAD value have been recorded by using handheld digital Chlorophyll Meter (SPAD 502 PLUS) after second spreading as indicator for the nitrogen distribution uniformity.

\section{RESULT AND DISCUSSION}

\section{Stationery mode experiments}

Three different fertilizers have been used to measure and visualize the distribution pattern and densities in stationery mode; Prilled urea $46 \% \mathrm{~N}$, Compound Fertilizer 14-14-14, and Muriate of Potash 0-0-60 (MOP), with tracking the differences of distribution density in both sides of the spreader. Different possible combinations settings of fertilizers types, spreading disk speeds, fins position on spreading disc, and dosage slide control arm have been used and results of stationery mode experiments are listed below. 


\subsection{Urea}

Distribution pattern of urea by the spreader was good. from 4.5 to $6 \mathrm{~m}$ effective (swath) width, the distribution is uniform and it is achievable with different setting in the spreader, also the rate of 12.5 to $50 \mathrm{~kg} /$ feddan as recommended amount for most field crops is easy to get with adjusting the sliding dosage arm, disc speed and direction of distribution (fins arrangement). For effective spreading width 4.5 to $6 \mathrm{~m}$, the speeding disc speed should be from 250 to $600 \mathrm{rpm}$. Uniform distribution pattern was obtained by adjusting spreader disc fins ( 1 fin in middle $/ 3$ end right) and spreading disc speed $550 \mathrm{rpm}$, this gave $6.6 \%$ as minimum differences on both sides for the amount distributes by the spreader (Table 3 and Fig. 4).

Table 3: Visualizing urea distribution density in gram per tray.

\begin{tabular}{|c|c|c|c|c|c|c|c|c|c|c|c|c|}
\hline \multirow{5}{*}{ 龅 } & \multicolumn{12}{|c|}{ Distribution amount of Urea, $\mathrm{g}$} \\
\hline & 0.00 & 0.00 & 0.00 & 0.00 & 0.00 & 0.00 & 0.00 & 0.00 & 0.00 & 0.00 & 0.00 & 0.00 \\
\hline & 0.00 & 0.00 & 0.00 & 8.91 & 15.47 & 36.81 & 28.13 & 11.86 & 6.63 & 2.36 & 0.00 & 0.00 \\
\hline & 0.00 & 0.00 & 0.00 & 14.07 & 25.32 & 45.48 & 31.62 & 14.91 & 5.35 & 2.04 & 0.00 & 0.00 \\
\hline & $\mathbf{0 . 0 0}$ & 1.76 & 11.50 & 45.11 & 108.9 & 160.2 & 138.7 & 69.99 & 23.24 & 4.80 & 0.62 & 0.00 \\
\hline 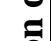 & 0.41 & 5.37 & 52.54 & 151.3 & 327.2 & 357.9 & 341.8 & 237.4 & 78.69 & 9.20 & 1.87 & 0.48 \\
\hline 을 & 1.61 & 13.18 & 132.4 & 365.4 & 310.3 & 220.9 & 224.7 & 315.5 & 130.8 & 50.76 & 6.06 & 0.66 \\
\hline 寻 & 2.12 & 50.80 & 263.1 & 248.6 & 162.4 & 49.18 & 29.61 & 125.3 & 338.5 & 106.4 & 13.55 & 1.12 \\
\hline ?=-2 & 6.61 & 68.05 & 320.02 & 92.57 & 22.50 & 16.11 & 23.51 & 65.94 & 169.45 & 160.6 & 28.86 & 2.40 \\
\hline .0 & 12.86 & 132.0 & 227.30 & 8.46 & 15.79 & 10.82 & 15.19 & 35.17 & 104.97 & 217.8 & 70.50 & 3.79 \\
\hline 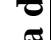 & 14.30 & 138.5 & 126.26 & 23.58 & 11.96 & 14.10 & 23.73 & 30.59 & 89.43 & 202.4 & 91.27 & 5.18 \\
\hline 幽 & 15.33 & 96.27 & 82.49 & 40.87 & 14.44 & 22.60 & 59.70 & 40.13 & 65.75 & 172.7 & 117.4 & 8.25 \\
\hline$\triangleright$ & 6.03 & 56.12 & 48.42 & 32.07 & 22.38 & 20.39 & 60.04 & 22.26 & 30.81 & 115.6 & 117.7 & 11.53 \\
\hline & 4.78 & 31.60 & 48.35 & 30.13 & 43.17 & 18.76 & 14.08 & 11.06 & 17.77 & 108.9 & 109.3 & 11.21 \\
\hline & 3.84 & 24.16 & 39.87 & 21.20 & 89.20 & 44.99 & 4.25 & 3.26 & 9.58 & 73.87 & 86.86 & 5.53 \\
\hline
\end{tabular}
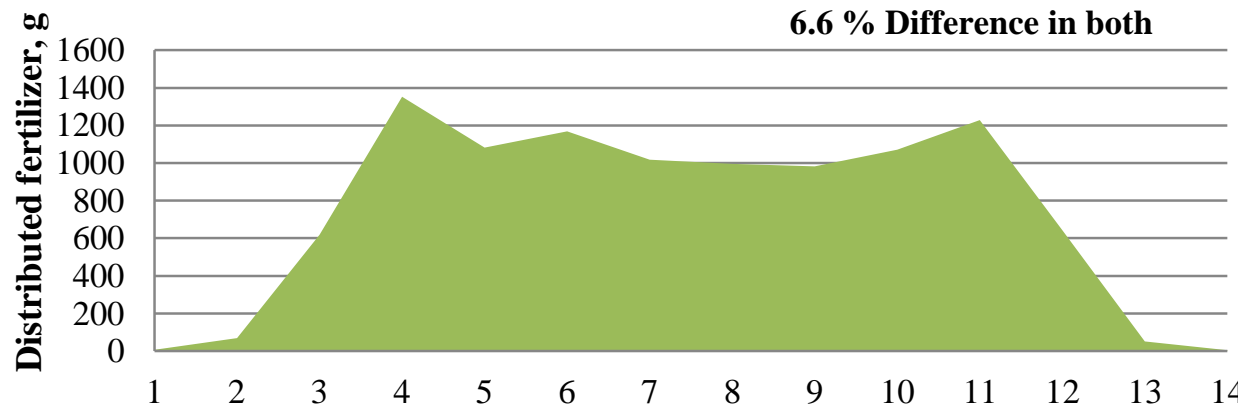

Trays arrangement

Urea distribution Pattern line and its density

Fig. 4 visualizing uniformity of distributed Urea and density 
For wider Urea spreading, maximum effective width can be achieved is $8.4 \mathrm{~m}$, that can be done with spreading disc speed $700 \mathrm{rpm}$ and disc fins should be 2 in center and 2 in their end right positions. Any minor changes in rotating disc' fins lead to uneven distribution (offside), e.g. spreading urea while all disc blades (fins) in middle lead to differences in distributed amount of 33\% (Table 4 and Fig. 5)

According to the amount needed of Urea, dosage slide control arm should be adjusted by moving it to deliver the required amount, after calibration the spreader with all possible delivering amounts, delivering rates followed a liners regression equation with 0.981 coefficients of determination (Fig. 6).

Table 4: Visualizing urea distribution density in gram per tray.

\begin{tabular}{|c|c|c|c|c|c|c|c|c|c|c|}
\hline & \multicolumn{10}{|c|}{ Distribution amount of Urea, $\mathrm{g}$} \\
\hline & 0.00 & 0.00 & 0.00 & 0.00 & 0.00 & 0.00 & 0.00 & 0.00 & 0.00 & 0.00 \\
\hline \multirow{15}{*}{ 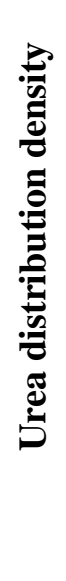 } & 0.00 & 0.00 & 0.00 & 0.30 & 0.66 & 1.84 & 1.26 & 0.08 & 0.08 & 0.11 \\
\hline & 0.00 & 0.00 & 0.00 & 0.62 & 3.69 & 3.05 & 3.76 & 1.21 & 0.31 & 0.00 \\
\hline & 0.00 & 0.08 & 0.23 & 5.00 & 7.28 & 9.74 & 5.09 & 0.80 & 0.47 & 0.06 \\
\hline & 0.00 & 0.00 & 0.48 & 5.26 & 17.09 & 33.64 & 13.59 & 4.82 & 1.47 & 0 \\
\hline & 0.00 & 0.20 & 3.85 & 23.00 & 42.56 & 16.56 & 21.39 & 3.19 & 1.12 & 0.00 \\
\hline & 0.00 & 0.13 & 2.78 & 18.23 & 19.76 & 9.11 & 20.83 & 19.31 & 4.65 & 0.20 \\
\hline & 0.00 & 1.33 & 14.15 & 38.27 & 29.89 & 8.16 & 25.22 & 12.80 & 1.22 & 0.03 \\
\hline & 0.00 & 0.00 & 15.40 & 26.50 & 13.25 & 12.34 & 17.45 & 17.63 & 5.83 & 85.00 \\
\hline & 0.08 & 1.67 & 26.85 & 40.45 & 6.44 & 6.38 & 11.55 & 11.11 & 1.89 & 0.00 \\
\hline & 0.00 & 0.19 & 11.56 & 32.77 & 14.84 & 4.36 & 10.00 & 17.92 & 9.88 & 0.61 \\
\hline & 0.06 & 4.27 & 24.92 & 21.72 & 17.07 & 10.42 & 13.87 & 12.67 & 3.19 & 0.10 \\
\hline & 0.00 & 0.16 & 10.24 & 19.72 & 21.89 & 37.12 & 9.32 & 4.19 & 19.86 & 0.48 \\
\hline & 0.03 & 3.43 & 28.38 & 18.69 & 43.12 & 38.27 & 6.37 & 13.31 & 4.45 & 0.10 \\
\hline & 0.00 & 0.72 & 10.01 & 21.57 & 15.68 & 32.15 & 10.09 & 6.85 & 12.50 & 1.34 \\
\hline & 0.12 & 2.87 & 7.78 & 8.65 & 9.04 & 17.96 & 4.69 & 8.01 & 3.37 & 0.02 \\
\hline
\end{tabular}

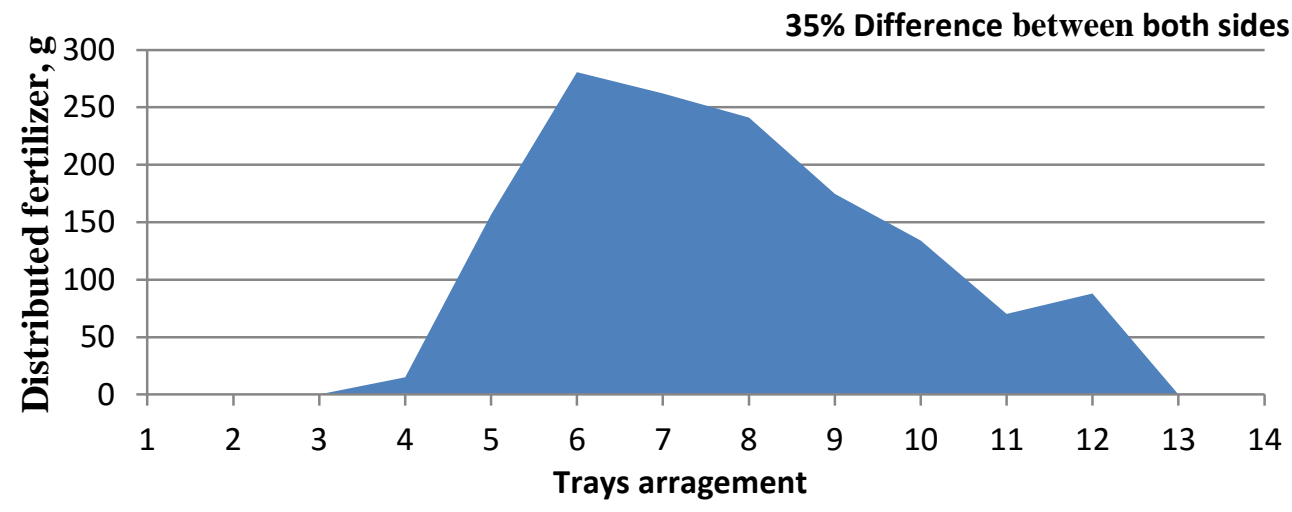

Offside Urea distribution Pattern line and its density

Fig. 5 visualizing offside distribution of Urea 


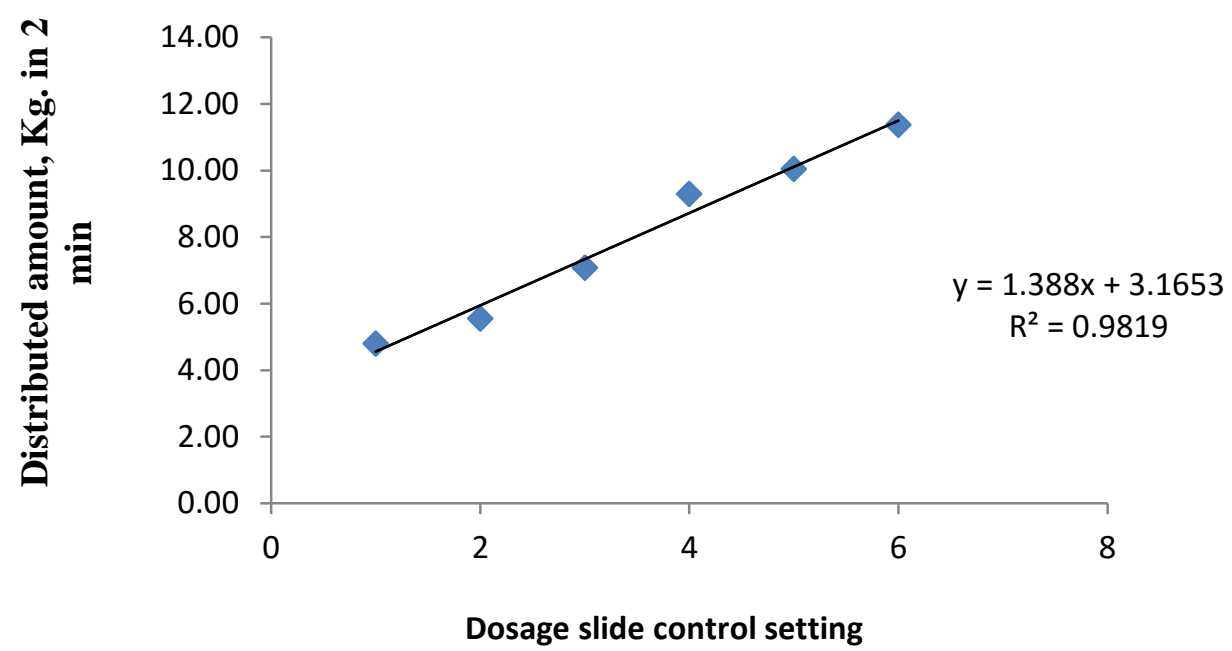

Fig. 6 Distributed amount of Urea from different dosing slide arm positions

\subsection{Compound Fertilizer 14-14-14}

For effective spreading width 4 to $6.6 \mathrm{~m}$, the fertilizer can be distributed effectively with $11 \%$ difference in both sides with suitable setting. Table 5 and Fig. 7 give the distribution pattern of compound fertilizer distributed in stationery mode with fins position of 1 in center and 3 at end right at $250 \mathrm{rpm}$ spreading disc speed.

Table 5: Visualizing compound fertilizer distribution density in gram per tray.

\begin{tabular}{|c|c|c|c|c|c|c|c|c|c|c|c|}
\hline \multirow{17}{*}{ 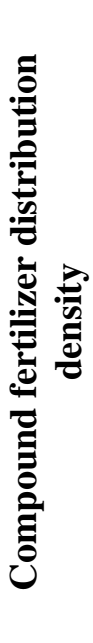 } & \multicolumn{11}{|c|}{ Distribution amount of compound fertilizer 14-14-14, g } \\
\hline & 0.0 & 0.0 & 0.0 & 0.0 & 0.0 & 0.0 & 0.0 & 0.0 & 0.0 & 0.0 & 0.0 \\
\hline & 0.0 & 0.0 & 0.0 & 0.0 & 0.0 & 0.0 & 0.0 & 0.0 & 0.0 & 0.0 & 0.0 \\
\hline & 0.0 & 0.0 & 0.0 & 0.0 & 0.0 & 0.0 & 0.0 & 0.0 & 0.0 & 0.0 & 0.0 \\
\hline & 0.0 & 0.1 & 0.1 & 0.2 & 0.2 & 0.5 & 0.5 & 0.0 & 0.0 & 0.0 & 0.0 \\
\hline & 0.0 & 0.0 & 0.1 & 0.9 & 1.1 & 3.0 & 1.4 & 0.6 & 0.4 & 0.0 & 0.0 \\
\hline & 0.2 & 1.3 & 3.4 & 4.4 & 9.1 & 3.7 & 3.3 & 84.0 & 0.0 & 0.0 & 0.0 \\
\hline & 0.2 & 1.5 & 6.1 & 16.4 & 20.3 & 70.0 & 40.4 & 12.6 & 2.3 & 0.5 & 0.2 \\
\hline & 0.7 & 5.1 & 22.6 & 37.5 & 101.0 & 69.1 & 74.3 & 39.5 & 8.9 & 1.5 & 0.5 \\
\hline & 2.0 & 9.5 & 51.0 & 106.7 & 228.0 & 353.9 & 117.0 & 70.3 & 32.4 & 7.6 & 1.0 \\
\hline & 3.4 & 23.4 & 98.2 & 195.7 & 423.0 & 537.5 & 337.2 & 186.0 & 59.9 & 11.0 & 0.5 \\
\hline & 4.0 & 31.6 & 163.5 & 308.6 & 400.4 & 499.3 & 694.3 & 303.0 & 125.9 & 24.2 & 3.0 \\
\hline & 9.5 & 29.4 & 139.1 & 345.3 & 257.0 & 99.2 & 155.3 & 382.5 & 147.6 & 34.3 & 2.0 \\
\hline & 9.6 & 36.6 & 107.4 & 240.8 & 44.3 & 24.1 & 37.0 & 245.6 & 185.6 & 64.5 & 10.0 \\
\hline & 7.8 & 33.5 & 82.0 & 58.0 & 29.0 & 24.0 & 24.0 & 97.6 & 185.7 & 76.0 & 17.4 \\
\hline & 3.3 & 14.0 & 42.3 & 32.6 & 24.0 & 21.1 & 42.0 & 59.7 & 15.5 & 91.7 & 21.5 \\
\hline & 2.0 & 7.1 & 12.4 & 15.3 & 29.0 & 12.1 & 11.1 & 24.5 & 70.1 & 40.4 & 18.1 \\
\hline
\end{tabular}




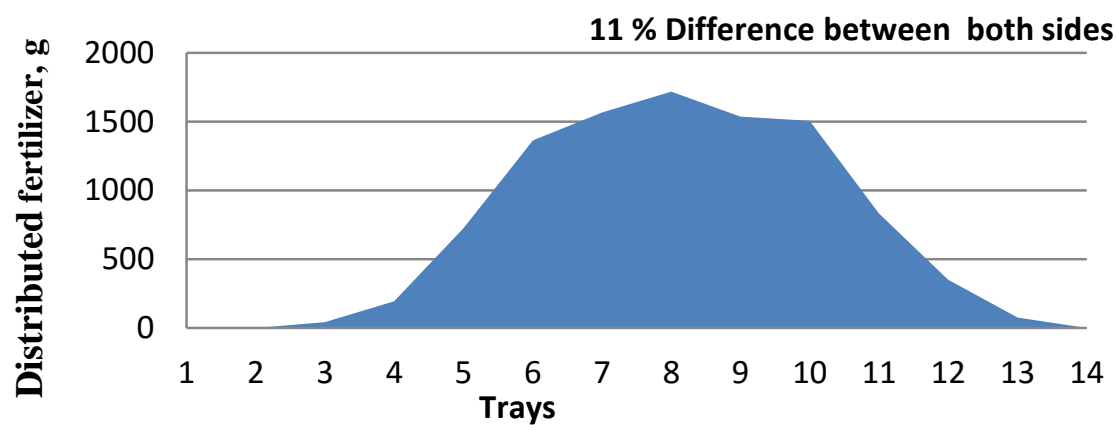

Distribution Pattern line for compound fertilizer

Fig. 7 visualizing distribution of compound fertilizer

For more spreading width, compound fertilizer can be distributed by the spreader with maximum 9.6 meter effective width when disc speed reaches $700 \mathrm{rpm}$ which is more than maximum width can be achieved with Urea. In this case the distribution pattern was more uniform compared to lower spreading width. Table 6 and Fig. 8 show the distribution pattern of compound fertilizer which gives $9.6 \mathrm{~m}$ effective width with $6 \%$ difference in amount for both sides, all 4 fins were in middle at this time. As the characteristics of compound fertilizer, recommended rate is from 80 to $100 \mathrm{~kg} /$ feddan is applicable for field crops which is achievable by the spreader. The rate needed can be calculated from the regression equation presented in Fig. 9, however, calibration of spreader is preferable before spreading.

Table 6: Visualizing Compound fertilizer distribution density in gram per tray at maximum width.

\begin{tabular}{|c|c|c|c|c|c|c|c|c|c|c|}
\hline \multirow{17}{*}{ 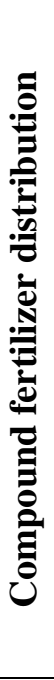 } & \multicolumn{10}{|c|}{ Distribution amount of compound fertilizer 14-14-14, $\mathrm{g}$ at maximum width } \\
\hline & 0.00 & 0.00 & 0.00 & 0.00 & 0.00 & 0.00 & 0.00 & 0.00 & 0.00 & 0.00 \\
\hline & 0.24 & 0.24 & 2.84 & 7.62 & 12.19 & 10.21 & 7.51 & 2.69 & 0.32 & 0.16 \\
\hline & 0.30 & 0.46 & 3.29 & 9.14 & 17.95 & 34.23 & 15.56 & 11.55 & 3.09 & 0.34 \\
\hline & 0.18 & 2.29 & 12.11 & 22.48 & 36.35 & 49.75 & 31.04 & 14.91 & 1.93 & 0.13 \\
\hline & 0.14 & 1.44 & 6.14 & 37.60 & 73.72 & 54.70 & 37.01 & 20.14 & 11.00 & 0.50 \\
\hline & 0.63 & 9.60 & 23.42 & 37.13 & 41.40 & 96.65 & 62.51 & 22.79 & 8.82 & 0.08 \\
\hline & 0.24 & 4.50 & 11.41 & 40.36 & 71.50 & 81.50 & 40.63 & 27.50 & 20.71 & 2.13 \\
\hline & 0.56 & 7.92 & 31.75 & 37.69 & 40.04 & 47.21 & 95.17 & 36.89 & 13.77 & 1.67 \\
\hline & 0.40 & 2.11 & 25.23 & 35.99 & 28.24 & 24.69 & 31.89 & 48.78 & 36.71 & 0.05 \\
\hline & 0.74 & 18.87 & 37.40 & 64.77 & 18.14 & 20.35 & 22.83 & 39.92 & 13.12 & 0.14 \\
\hline & 0.14 & 5.44 & 27.58 & 20.54 & 33.40 & 19.92 & 28.63 & 36.93 & 38.93 & 7.03 \\
\hline & 1.37 & 11.03 & 44.00 & 23.60 & 45.50 & 38.74 & 42.81 & 35.11 & 22.08 & 2.18 \\
\hline & 0.08 & 2.48 & 24.57 & 28.08 & 45.41 & 110.82 & 44.02 & 30.41 & 46.70 & 5.92 \\
\hline & 0.59 & 11.35 & 24.85 & 23.55 & 94.29 & 159.14 & 31.57 & 50.77 & 15.14 & 1.22 \\
\hline & 0.45 & 3.09 & 7.72 & 14.30 & 34.54 & 84.30 & 36.99 & 49.53 & 34.00 & 4.54 \\
\hline & 0.07 & 2.62 & 4.40 & 9.23 & 22.71 & 32.91 & 21.13 & 30.88 & 15.05 & 1.50 \\
\hline
\end{tabular}


$6 \%$ Difference between both sides

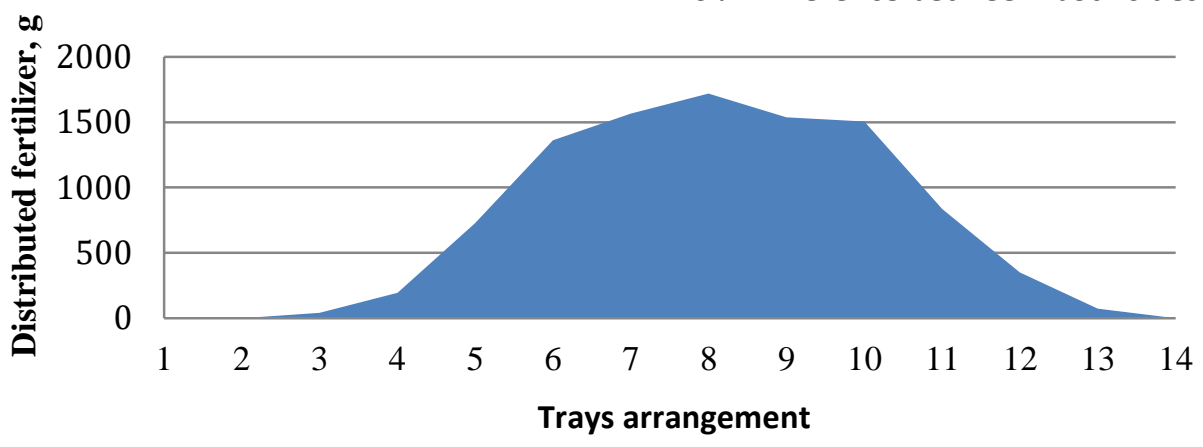

Distribution pattern line for compound fertilizer

Fig. 8 Visualizing distribution of compound fertilizer at maximum spreading width

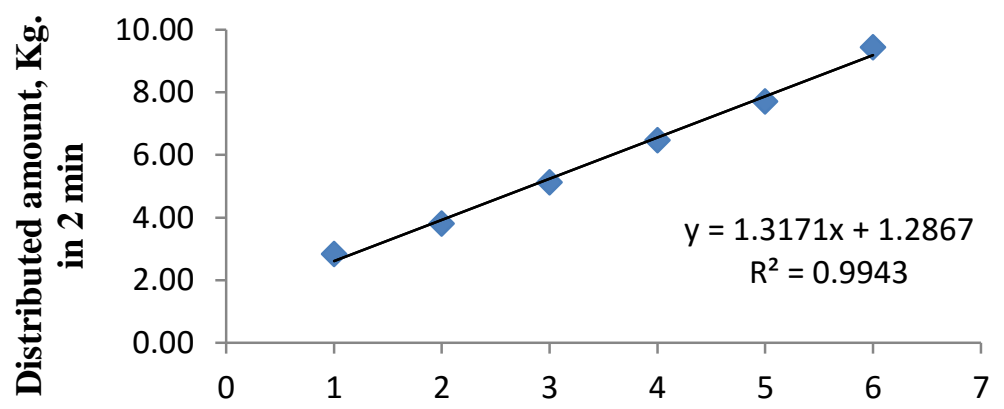

Dosage slide control setting

Fig. 9 Distributed amount of compound fertilizer from different dosing slide arm positions

\subsection{Muriate of Potash 0-0-60 (MOP)}

MOP as a fine crystal fertilizer with recommended amount less than 20 $\mathrm{kg} /$ feddan in most of fields not easy to be distributed by the spreader under $4 \mathrm{~km} / \mathrm{h}$ forward speed or less. On the other hand, The MOP gave bad uniformity while distributed by the spreader under all setting, which make it difficult to be distributed under the current spreader without further modification in both of the dosage slide setting and/or spreading disc. Table 7, Fig. 10 and Fig.11 present the poor spreading pattern of MOP. However, data of calibrated amount of each dosage slide setting and its liner regression equation is presented in Fig. 12. 


\section{Field experiments}

Two times spreading have been applied to experimental plots after transplanting rice crop to compare between the spreader as mechanical method of spreading the fertilizers and traditional spreading method (manual), and to see the effect of different rates on field distribution pattern. For spreader, three levels have been chosen as 100, 75 and 50\% of recommended rate, for manual $100 \%$ of recommended rate was applied only. However, the recommendation was to apply fertilizers on three times, but in third time, the rice crop is being at maturity stage and subjected to damage if a carriage that carry the spreader try to pass in.

Table 7: Visualizing Muriate of potash distribution density in gram per tray at maximum width.

\begin{tabular}{|c|c|c|c|c|c|c|c|c|c|c|c|}
\hline \multirow{15}{*}{ 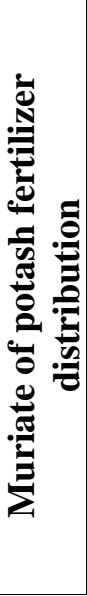 } & \multicolumn{11}{|c|}{ Distribution amount of Muriate of potash, $\mathrm{g}$} \\
\hline & 0.0 & 0.0 & 1.3 & 6.6 & 11.9 & 11.8 & 8.4 & 5.0 & 4.3 & 0.0 & 0.0 \\
\hline & 0.1 & 1.0 & 4.6 & 12.1 & 23.7 & 27.4 & 18.8 & 13.2 & 9.2 & 3.2 & 0.1 \\
\hline & 0.1 & 1.4 & 9.8 & 24.2 & 42.1 & 48.4 & 34.7 & 27.2 & 13.3 & 4.5 & 1.4 \\
\hline & 0.0 & 2.6 & 16.5 & 46.5 & 69.2 & 68.3 & 51.1 & 32.4 & 23.9 & 11.7 & 2.4 \\
\hline & 0.1 & 4.6 & 34.3 & 70.9 & 104.0 & 96.9 & 74.4 & 48.2 & 32.7 & 17.2 & 3.5 \\
\hline & 0.9 & 10.1 & 51.4 & 154.5 & 143.8 & 84.4 & 68.7 & 55.0 & 29.7 & 18.7 & 7.4 \\
\hline & 1.2 & 9.9 & 38.7 & 120.1 & 139.8 & 97.2 & 47.3 & 48.7 & 44.8 & 25.5 & 11.6 \\
\hline & 1.3 & 13.7 & 59.0 & 86.6 & 100.6 & 72.7 & 45.4 & 42.6 & 38.8 & 18.1 & 9.8 \\
\hline & 1.6 & 10.0 & 45.8 & 75.4 & 71.7 & 44.0 & 34.4 & 29.9 & 29.5 & 22.8 & 8.5 \\
\hline & 2.7 & 8.4 & 37.6 & 74.8 & 37.3 & 25.8 & 15.3 & 22.6 & 25.1 & 18.4 & 7.9 \\
\hline & 2.2 & 10.1 & 29.6 & 43.0 & 33.3 & 20.3 & 8.5 & 14.0 & 18.0 & 24.3 & 4.5 \\
\hline & 1.8 & 7.1 & 21.8 & 42.2 & 33.0 & 14.9 & 2.2 & 27.1 & 32.9 & 18.6 & 4.8 \\
\hline & 0.9 & 3.8 & 17.4 & 41.4 & 49.7 & 6.2 & 1.5 & 9.9 & 7.8 & 11.8 & 2.9 \\
\hline & 1.5 & 4.1 & 13.3 & 33.4 & 58.5 & 6.2 & 0.7 & 3.7 & 7.2 & 7.5 & 2.3 \\
\hline
\end{tabular}

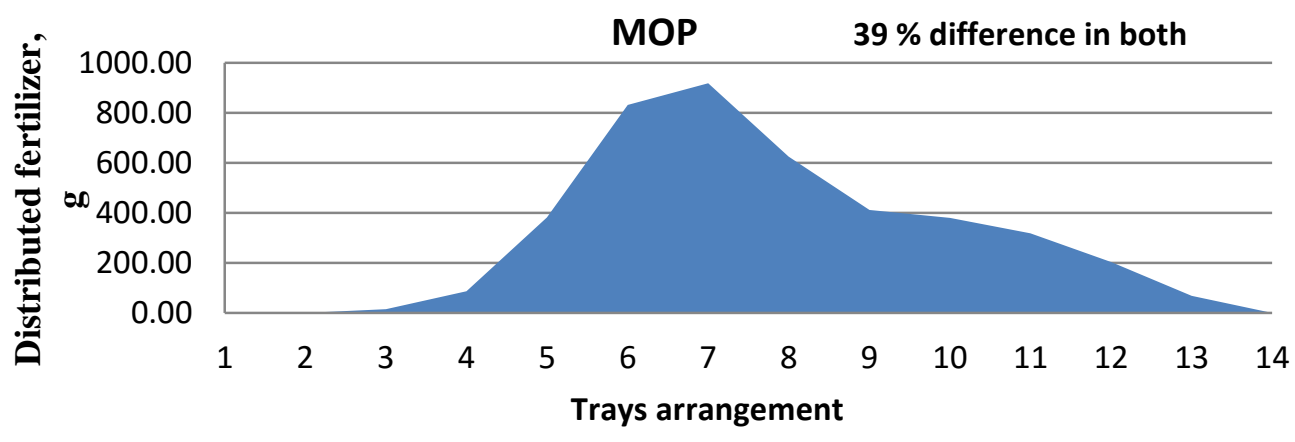

Fig. 10 Distributed amount of compound fertilizer from different dosing slide arm positions 


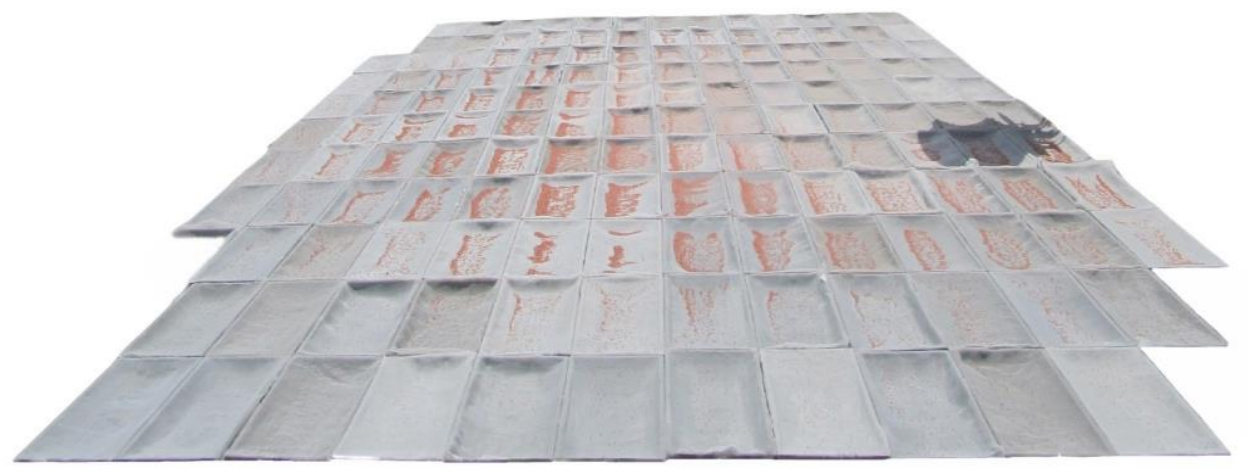

Fig. 11 Poor spreading pattern for MOP

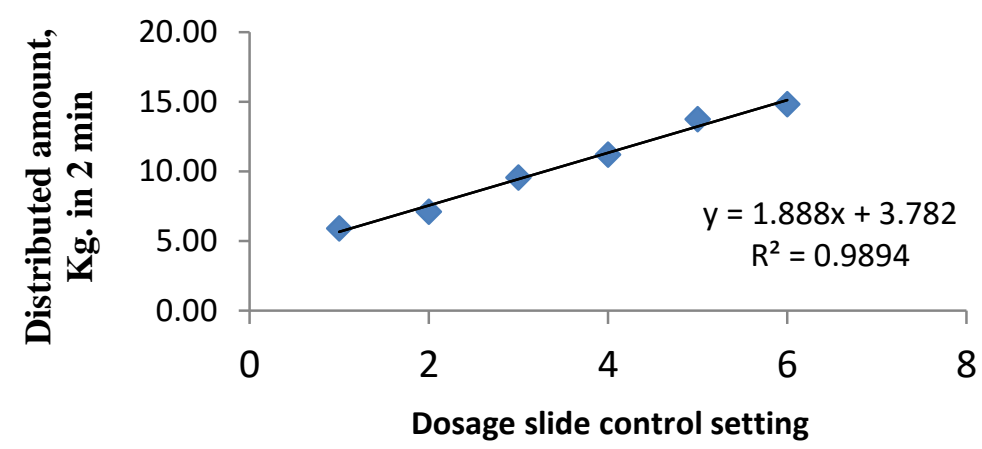

Fig. 12 Distributed amount of MOP from different dosing slide arm positions

\subsection{Distribution uniformity}

First spreading don by using compound fertilizer in all plots with 90 $\mathrm{kg} /$ Feddan recommended rate. Setting for spreading that amount obtained earlier from the best distribution pattern obtained from stationery mode experiments, where fins position as of 1 in center and 3 at end right at 250 rpm spreading disc speed is one of settings can achieve the favorable effective swath width of $5.5 \mathrm{~m}$.

Average amount distributed in both sides of the spreader showed that percentages of differences in both spreading sides were 13.62, 12.56 and $40.85 \%$ for application rates 50,75 , and $100 \%$ respectively. While in manually broadcasting fertilizers, one side was higher than the other side by $146.51 \%$ in average as shown in Fig. 13 Patterns of distributed fertilizer by spreader for 100,75 , and $50 \%$ of recommended amount and manual spreading as in Fig. 14. 


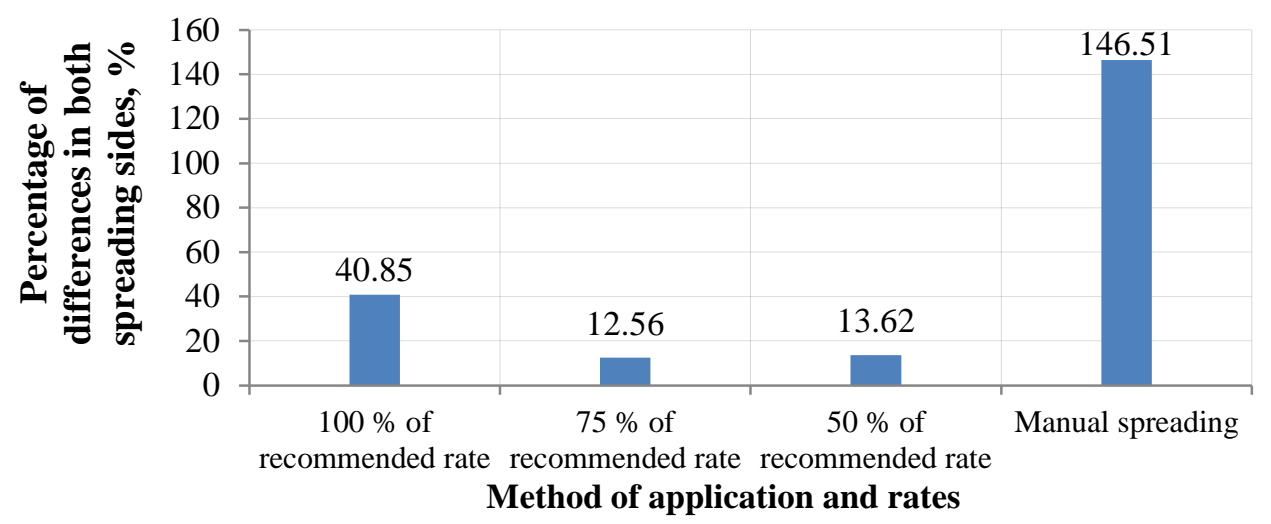

Fig. 13 Percentage of differences in both spreading sides for mechanical and manual compound fertilizer application at different rates

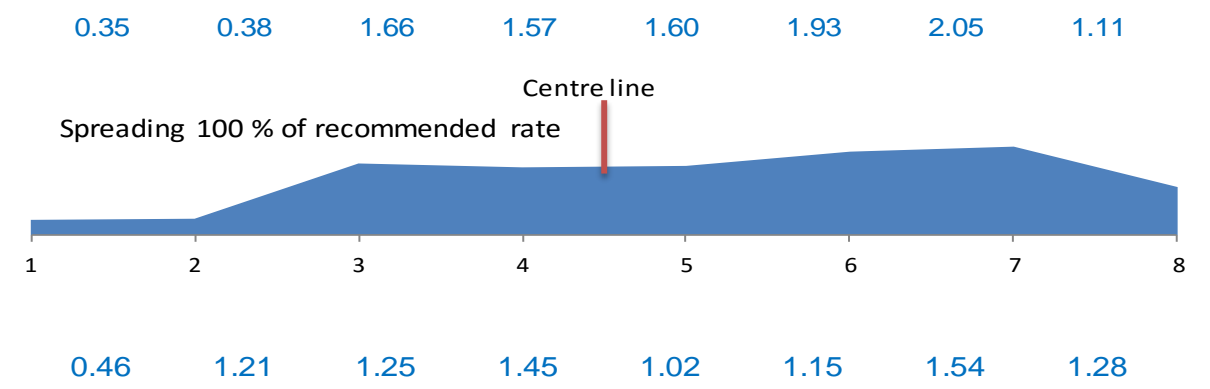

Spreading $75 \%$ of recommended rate
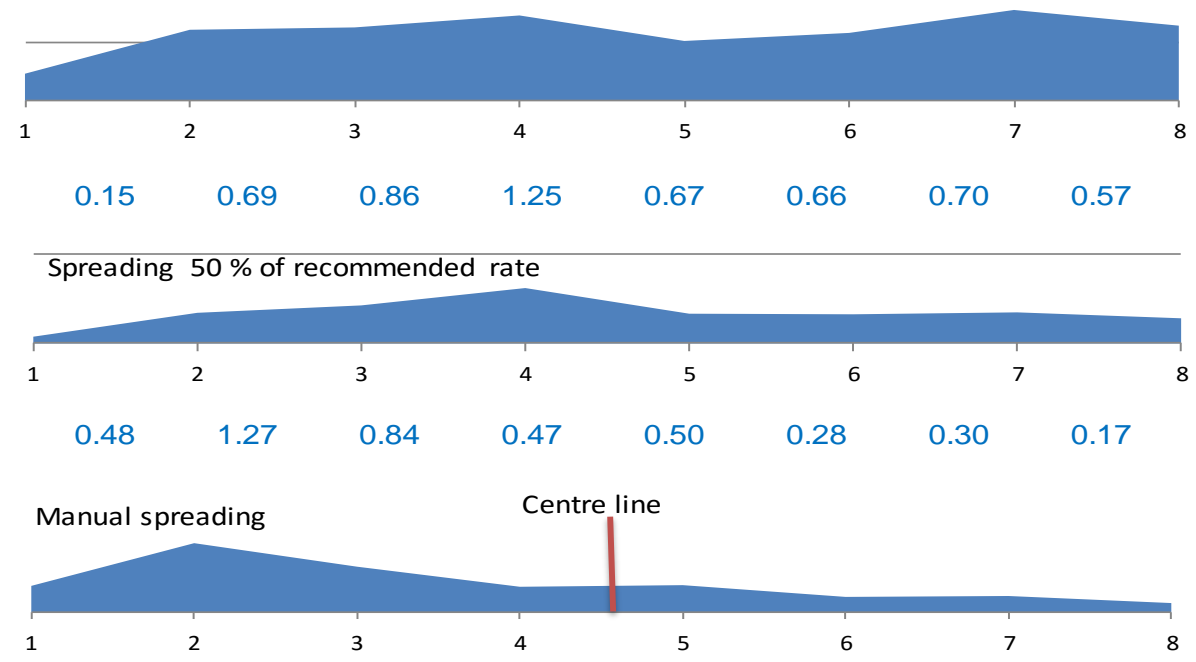

Fig. 14 Patterns of distributed compound fertilizer by spreader for 100,75 , and $50 \%$ of recommended amount and manual spreading 
In second spreading by the manufactured spreader, spreading don by using Urea fertilizer in all plots with recommended rate. Spreader has been adjusted by placing 1 fin in middle $/ 3$ end right on spreading disc and spreading disc speed $550 \mathrm{rpm}$ to have $5.5 \mathrm{~m}$ effective swath length as set for field experiments. Average amount distributed in both sides of the spreader showed more variation in spreading pattern and percentages of differences in both spreading sides were 26.6, 32.1 and $27.9 \%$ for application rates 50, 75, and $100 \%$ respectively. While in manually broadcasting fertilizers, one side was higher than the other side $44.5 \%$ in average as shown in Fig. 15

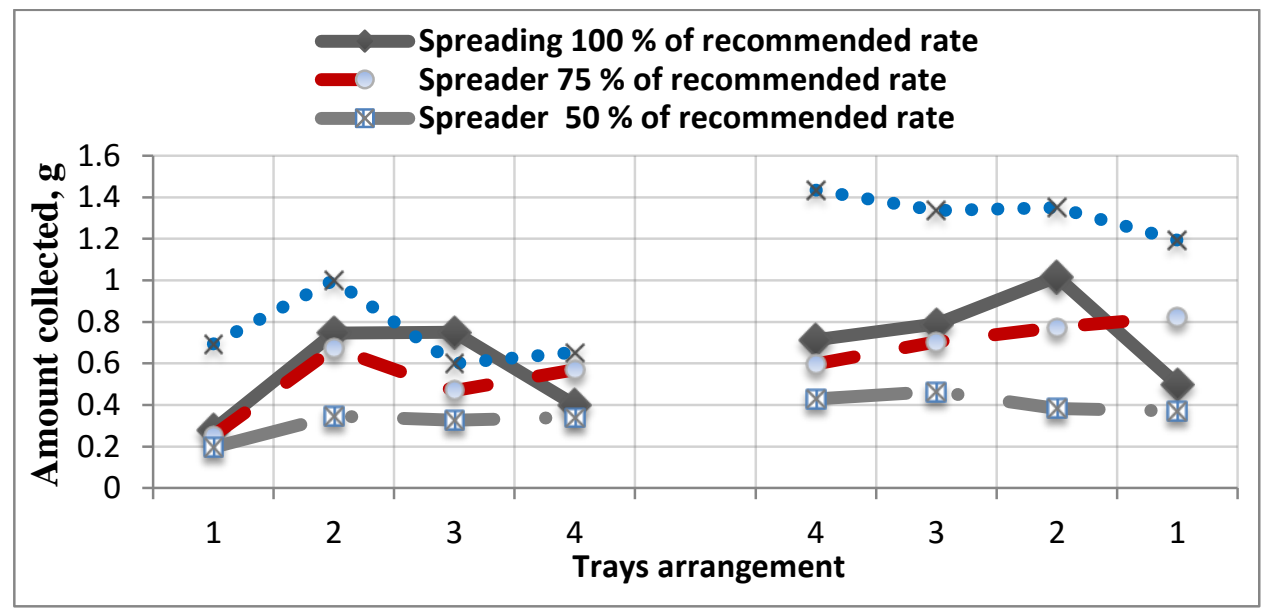

Fig. 15 Patterns of distributed Urea fertilizer by spreader for 100, 75, and $50 \%$ of recommended amount and manual spreading

\subsection{Maximum effective spreading width}

For testing maximum effective swath width during spreading, spreading disc speed $700 \mathrm{rpm}$ was used and 2 disc fins located in center and 2 in their end right for both urea and compound fertilizer. Averages of percentage of differences in both sides were 27 and $0.4 \%$ for Urea and compound fertilizer respectively (Fig. 16).

\subsection{Chlorophyll}

As the distribution pattern recorded the time of spreading, the Chlorophyll values also recorded after second spreading as indicator to address the variability of distributing the fertilizers for specific application rates. 

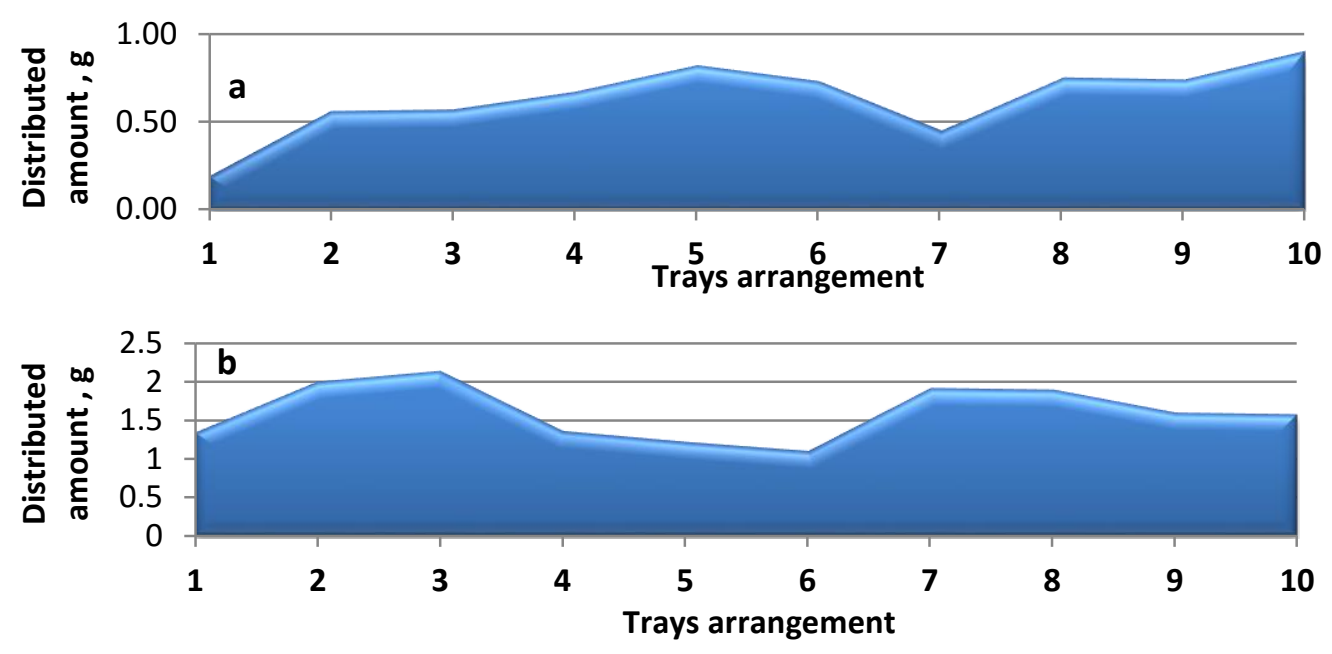

Fig. 16 Patterns of distributed Urea fertilizer (a) and compound fertilizer (b) with maximum width of $100 \%$ of recommended rate

Average SPAD values showed no significant differences within each subplot and in different locations for all application rates. The maximum difference between average lowest and highest SPAD values for plots that have been spread by the machine was $8 \%$ when the machine was spreading $75 \%$ of recommended rate. Lowest values were 3 and $4 \%$ for 50 and $100 \%$ of recommended rates. In manual broadcasting there was difference of $15 \%$ between lower and highest value of SPAD in different plot locations (Fig. 17).
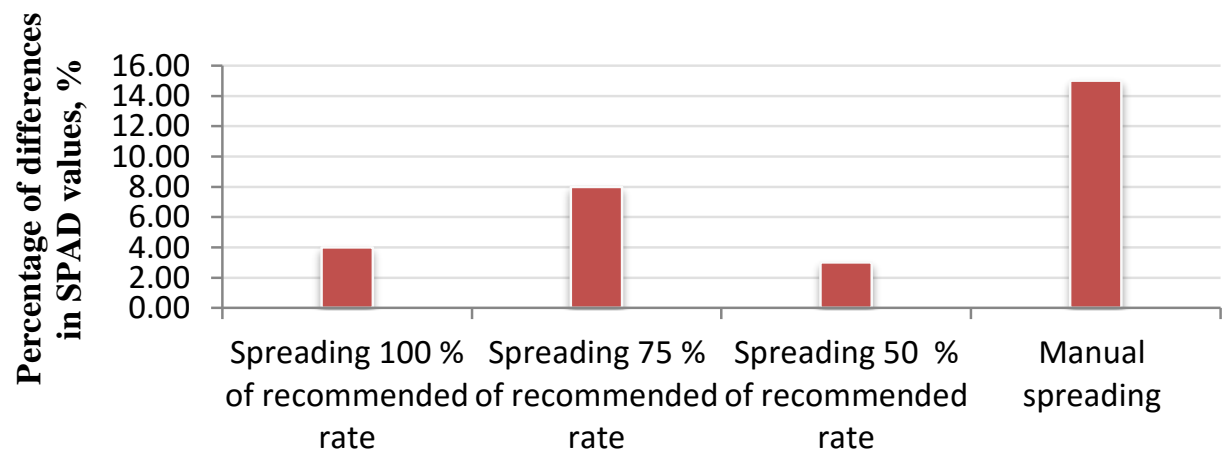

Spreading variables

Fig. 17 Percentage of differences in SPAD values for different spreading variable 


\section{CONCLUSION}

Using the manufactured tractor-mounted spreader consider good option to apply different fertilizers using tractor in field. The designed spreader could be controlled easily with attaching electric-electronic circuits to adjust the spreading disc rotational speed as well controlling the close and open gate of the fertilizer in the hopper. The Distribution pattern of urea by the spreader was very uniform and can be obtained with adjusting the spreader setting to have effective spreading (swath) width from 4.5 to $6 \mathrm{~m}$ and up to $8 \mathrm{~m}$. also different rate of fertilizers can be used. For compound fertilizer, the uniformity was even better because of the fertilizer shape and properties. Both short and wide spreading width can be achieved by the spreader. For MOP, Spreader cannot achieve uniformity with fine crystal fertilizers (fine powder too) which have two components with different particle sizes and densities, also, difficult to deliver such fertilizers with lower application rates. In field, the pattern of fertilizers distribution is acceptable and better than the distribution pattern obtained by manual broadcasting and has been confirmed by measuring the Chlorophyll in rice crop leaves. The only challenge may appear is using the distributor attached to a tractor in difficult soil condition as in case of wet soil applications.

\section{REFERENCES}

Cool, S., J. Pieters, K.C. Mertens, B. Hijazi, J. Vangeyte (2014). A simulation of the influence of spinning on the ballistic flight of spherical fertiliser grains. Computers and Electronics in Agriculture 105: 121-131.

Hao, L. V., Y. U. Jianqun and F.U. Hong (2013). Simulation of the operation of a fertilizer spreader based on an outer groove wheel using a discrete element method. Mathematical and Computer Modelling 58: 842-85.

Hofstee, J. W. (1993) Handling and spreading of fertilizer part 3, measurement of particle velocities and direction with Ultra Sonic transducers theory. J. of Agric. Eng. Res., 58 (1): 1-16.

Hassan M. A., M. M. Morad, H. G. Gweifel and M. A. Tawfik (2005). 
Development of the manure fertilizing machine to improve its distribution pattern for spreading different types of fertilizers. Zagazig J. of Agric. Res. 32 (6):1913-1932.

Larry S. and V. A. Bandel (2002). Uniform lime and fertilizer spreading. Maryland cooperative extension. Col. of Agric., and natural resources, Univ., of Maryland. USA.

Lawrence, H. G., I. J. Yule and R. I. Murray (2006). Calculating Field CV's for Centrifugal Spreaders. G1 - G5. $2^{\text {nd }}$ International Symposium on Centrifugal Fertiliser Spreading, from academic to applied research. Oct 24-25, Cemagref-Pole Epandage Environment, 03150, Montoldre, France.

M orad, M . M . (1990). Basic requirements in the design and development of the fertilizer broadcasting spreader. Misr J. Agric. Eng., 7 (4): 402-411.

ISO (1983). ISO 5690 Equipment for distributing fertilisers test methods: part 1: full width fertiliser distributors. International Organization for Standardization Standards Handbook 13, Agricultural Machinery, pp. 373-386.

Parris, K. and L. Reille (1999). Measuring the environmental impacts of agriculture: use and management of nutrients. Proceedings no. 442. The International Fertiliser Society, York, UK.

Persson, K. (1998). Physical qualities of fertilisers and variable rate spreading-interactions. Proceedings no. 424. The International Fertiliser Society, York, UK.

Piron, E., D.Miclet and S. Villette (2010) CEMIB: an innovative bench for spreader eco-design, Proceedings International Conference on Agricultural Engineering, AgEng2010, Clermont-Ferrand, France, 6-8 September.

Prummel, J. and P. Datema (1962). Strooiregelmaat van kunstmeststrooiers en de betekenis daarvan voor de opbrengst "Regularity of spreading of artificial fertiliser spreaders and the meaning thereof to yield". Landbouwmechanisatie, 13, 742-753.

Reumers, J., E. Tijskens and H. Ramon (2003). Experimental Characterisation of the Cylindrical Distribution Pattern of Centrifugal Fertiliser Spreaders: towards an Alternative for 
Spreading Hall Measurements. Biosystems Engineering 86 (4), 431439.

Sogaard, H. T. and P. Kierkegaard (1994). Yield reduction resulting from uneven fertilizer distribution. Transactions of the ASAE, 37(6), 1749-1752.

Yildirim, Y. and M. Kara (2003). Effect of vane height on distribution uniformity in rotary fertiliser spreaders with different flow rates. Applied Engineering in Agriculture, 19 (1), 19-23.

الملخص العربى

تطوير واختبار آلة محمولة علي الجرار لتوزيع السماد الكيماوي

د. احمد محمد الشيخة • د. رشاد عزيز حجازي٪

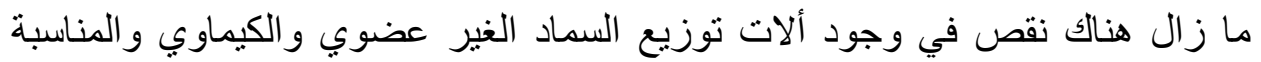

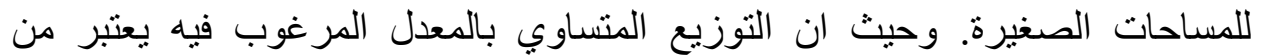

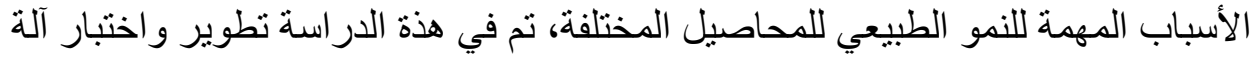

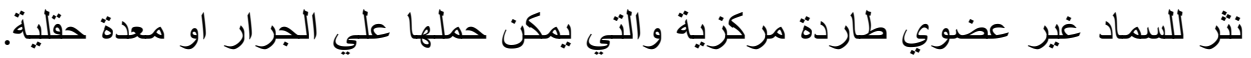

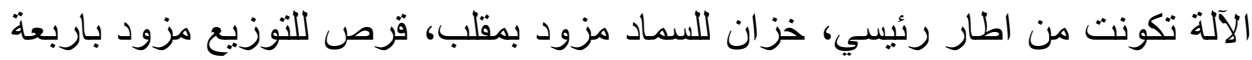

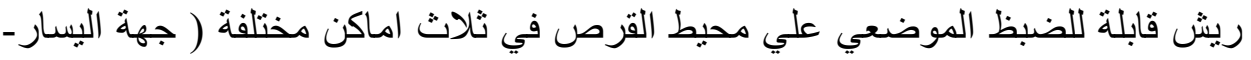

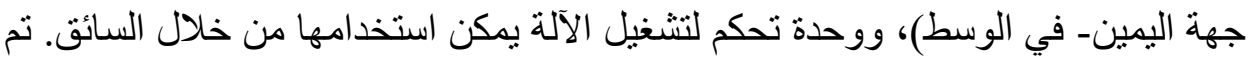

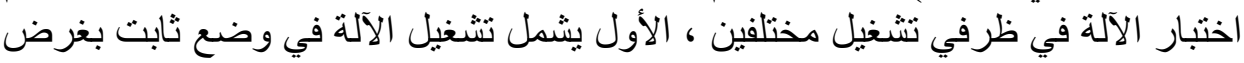

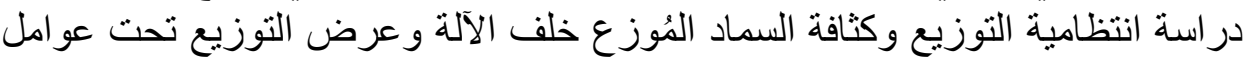

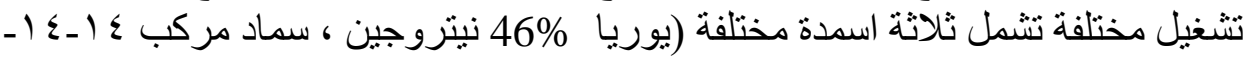

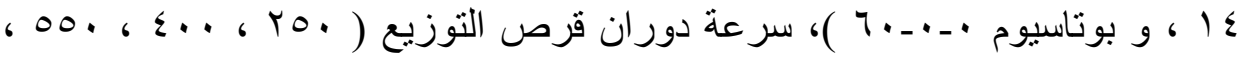

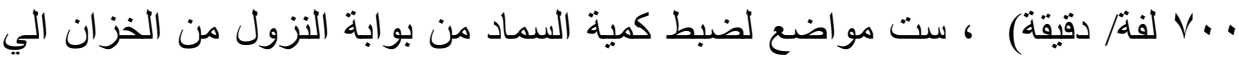

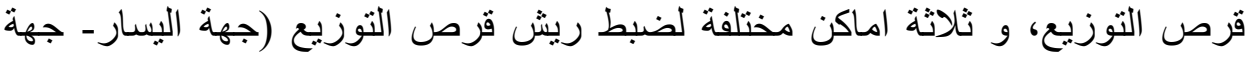

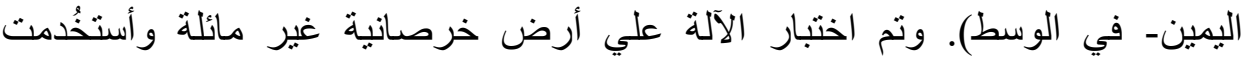

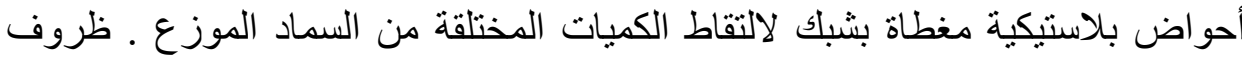

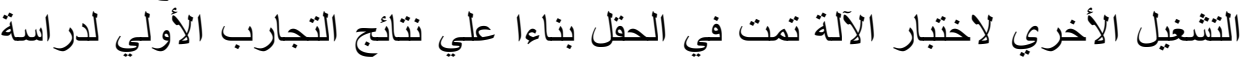

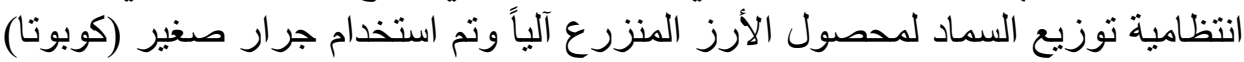

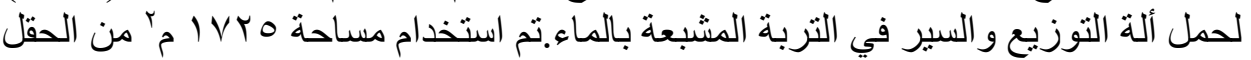

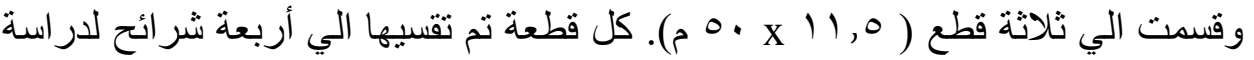

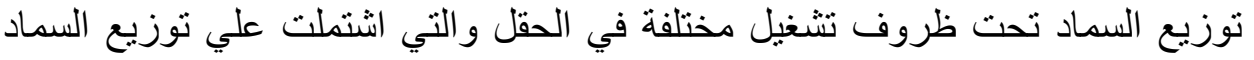

• مدرس الهندسة الزراعية ـ كلية الزراعة ـ جامعة دمياط

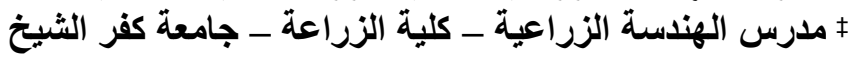




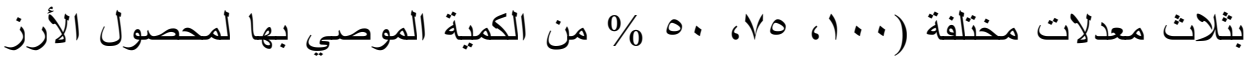

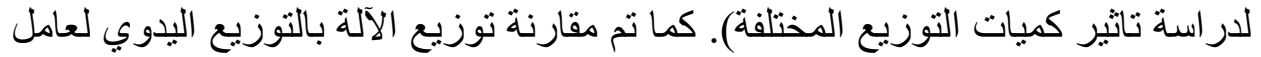

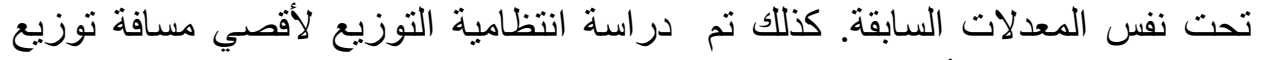

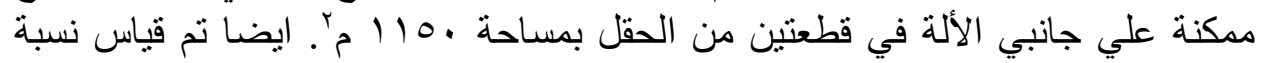

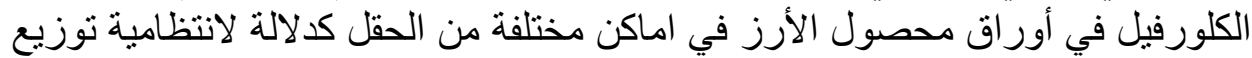

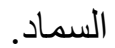

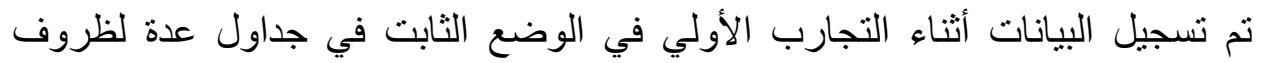

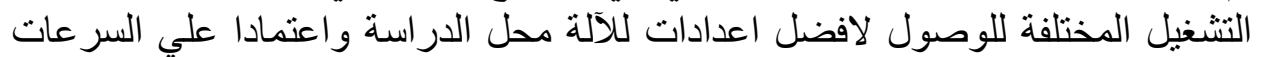

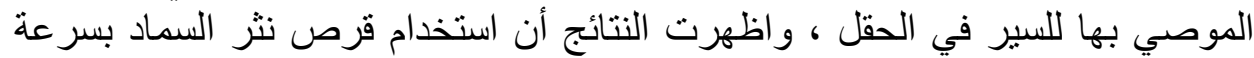

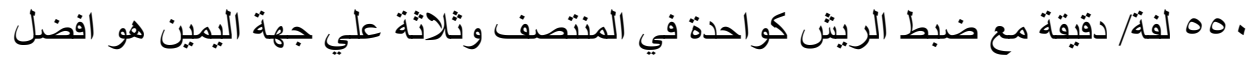

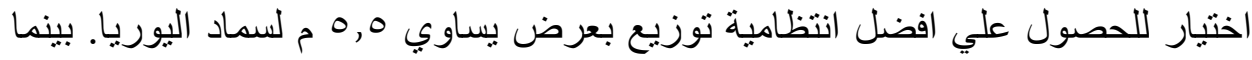

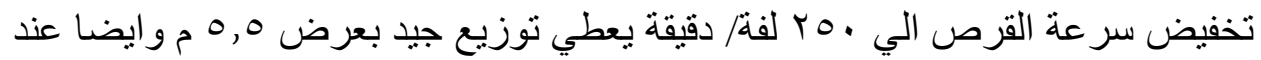

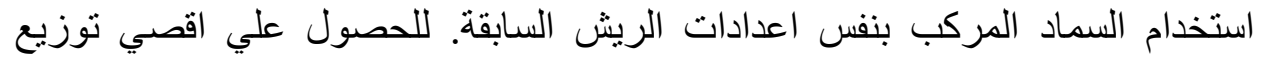

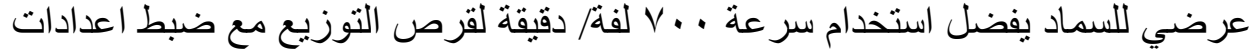

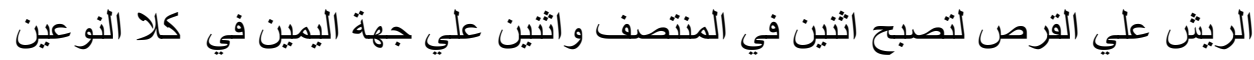

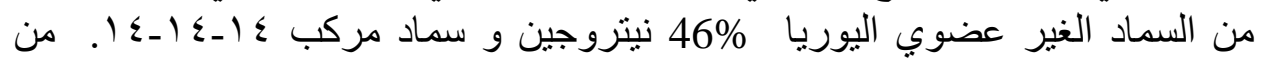

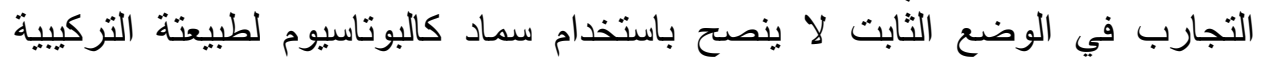

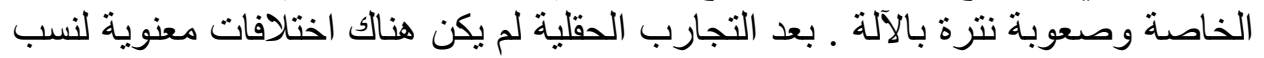

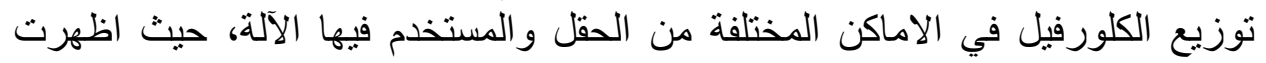

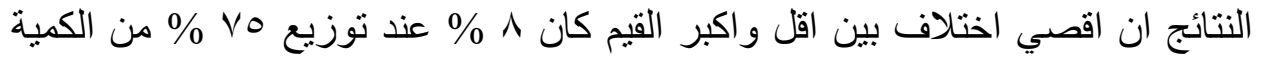

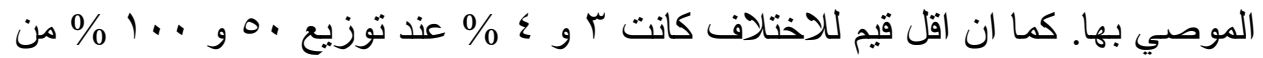

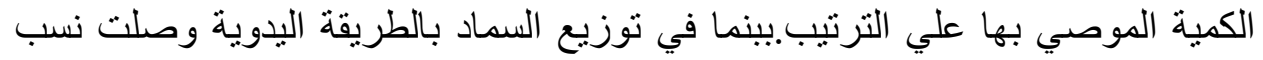

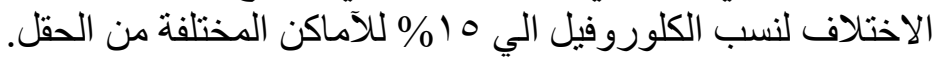

